\title{
GOOGLE SCHOLAR METRICS, PENGARUHNYA PADA PENGELOLAAN JURNAL ILMIAH
}

\author{
Karmila Pare Allo* \& La Ode Ismail Ahmad**
}

\begin{abstract}
*Program Pascasarjana Ilmu Perpustakaan, Universitas Islam Negeri Alauddin Makassar **Program Pascasarjana Ilmu Hadis, Universitas Islam Negeri Alauddin Makassar Email: pareallokarmila@gmail.com, laode.ismail@uin-alauddin.ac.id
\end{abstract}

(Submitted: 02-02-2020, Revised: 23-06-2020, Accepted: 27-06-2020)

DOI: $10.24252 /$ kah.v8i1a10

\begin{abstract}
ABSTRAK: Google Scholar merupakan mesin pencari yang membantu akademisi untuk menelusuri karya tulis ilmiah, seperti artikel jurnal yang telah diterbitkan di mana saja. Selain itu, media ini juga dapat digunakan oleh akademisi atau jurnal ilmiah untuk mengukur metrik perkembangan sitasinya dengan membuat profil pada Google Scholar Profile. Penelitian ini akan menggambarkan; 1) metrik sitasi Khizanah al-Hikmah : Jurnal Ilmu Perpustakaan, Informasi, dan Kearsipan (KAH-JIPIK), 2) jenis dokumen yang paling banyak menyitir, 3) artikel yang paling sering disitir, dan 4) manfaat yang dirasakan oleh KAH-JIPIK pada Google Scholar Metrics (GSM). Data penelitian diperoleh dari hasil wawancara dengan jurnal manajer dan GSM dari KAH-JIPIK. Microsoft Excel digunakan untuk mengalkulasi dan memberikan grafik sitasi. Hasil penelitian ini menunjukkan bahwa terjadi penurunan sitiran yang diperoleh dari tahun ke tahun, jenis dokumen yang menyitir artikel Khizanah Al-Hikmah adalah jurnal, skripsi, tesis, prosiding, makalah, buku dan sumber lainnya, artikel yang paling banyak disitir adalah yang ditulis oleh Machsun Rifauddin dengan jumlah sitiran sebanyak 30. Penelitian dapat berimplikasi pada strategi untuk memaksimalkan lagi agar para pembaca tertarik untuk menyitir jurnal ini. Jurnal ini juga perlu memaksimalkan kualitas artikel yang diterimanya, khususnya yang berkaitan dengan perkembangan bidang yang berkaitan.
\end{abstract}

Kata kunci: Google Scholar Metrics; sitiran; bibliometrika

\section{GOOGLE SCHOLAR METRICS: ITS INFLUENCE ON ACADEMIC JOURNAL MANAGEMENT}

ABSTRACT: Google Scholar helps academicians to explore scholarly papers, such as academic articles that have been published everywhere. In addition, this tool can also be used by authors or journals to measure their citations trend by creating their own Google Scholar Profile. This research will describe; 1) Google Scholars Metrics of Khizanah al-Hikmah: Journal of Library, Information, and Archival Science (KAH-JIPIK), 2) the types of documents that have cited the most, 3) the most cited articles, and 4) the benefit of Google Scholar Metrics. The research data were obtained from interviews with its journal manager and KAH-JIPIK's Google Scholar profile. MS. Excel was used to help to calculate and provide citation charts. The results of this study indicate that there was a decrease trend in citations from year to year, the types of documents citing Khizanah Al-Hikmah articles were journals, theses, proceedings, papers, books, and other sources, and the most cited article was written by Machsun Rifauddin with a total of 30 citations. This study might have strong reccommendations for the journal to maximize the promotion so the readers are interested in citing the published articles. The journal also needs to maximize the quality of submitted articles, particularly related to the development of the fields.

Keywords: Google Scholar Metrics; citation; bibliometric 


\section{PENDAHULUAN}

Tren perkembangan suatu disiplin ilmu kini dapat dilihat, diamati dan diteliti melalui artikel ilmiah atau hasil penelitian ilmiah yang diterbitkan pada beragam bentuk publikasi seperti buku, prosiding, ataupun jurnal. Hasil penelitian, seperti skripsi, tesis, disertasi dan karya ilmiah lainnya juga dapat digunakan untuk menggambarkan sejauh mana topik-topik riset yang dikaji pada tiaptiap karya tulis ilmiah tersebut mengalami perkembangan dari waktu ke waktu. Dengan mengamati tren tersebut, maka suatu disiplin ilmu bisa memprediksi dan mengarahkan atau bahkan mengembangkan riset-riset selanjutnya.

Saat ini, hampir setiap akademisi tidak mengenal yang namanya Google Scholar, yaitu mesin pencari karya-karya tulis ilmiah (berbeda dengan google yang pada umumnya digunakan netizen) di mana salah satu fiturnya ialah setiap penulis ataupun setiap jurnal ilmiah dapat membuat profil untuk mengindeks dan mengukur setiap publikasi yang belum atau telah diterbitkan, selama itu merupakan karya tulis ilmiah. Ini dikenal dengan Google Scholar Metrics (GSM), media atau tool di mana penulis atau pengelola jurnal dapat melihat seberapa banyak sitasi atau kutipan yang telah diperolehnya. Baik bagi penulis maupun jurnal ilmiah, manfaat dari GSM ini sangat signifikan. Misalnya, bagi seorang penulis yang melihat siapa yang mensitasi/mengutip karyanya, artinya karya tulisnya memberikan kontribusi nyata pada tulisan lainnya. Begitu pula pada jurnal ilmiah. Kontribusi atau dampak tersebut sering diistilahkan dengan impact factor (Lariviere \& Sugimoto, 2018). Terkhusus bagi jurnal ilmiah, impact factor ini sangat diperlukan sebagai media untuk evaluasi.

Tidak sedikit jurnal-jurnal ilmiah yang ada di Indonesia, khususnya yang menggunakan software Open Journal System (OJS) termasuk Khizanah al-Hikmah (Karmila, 2019) menggunakan dan menampilkan GSM pada situs-situs jurnalnya. Dari beberapa yang peneliti amati, GSM ini biasanya diletakkan pada bagian bawah atau samping laman web jurnal yang berlogokan Google Scholar. Termasuk Khizanah al-Hikmah : Jurnal Ilmu Perpustakaan, Informasi, dan Kearsipan (KAH-JIPIK) seperti yang terlihat pada gambar di bawah ini.

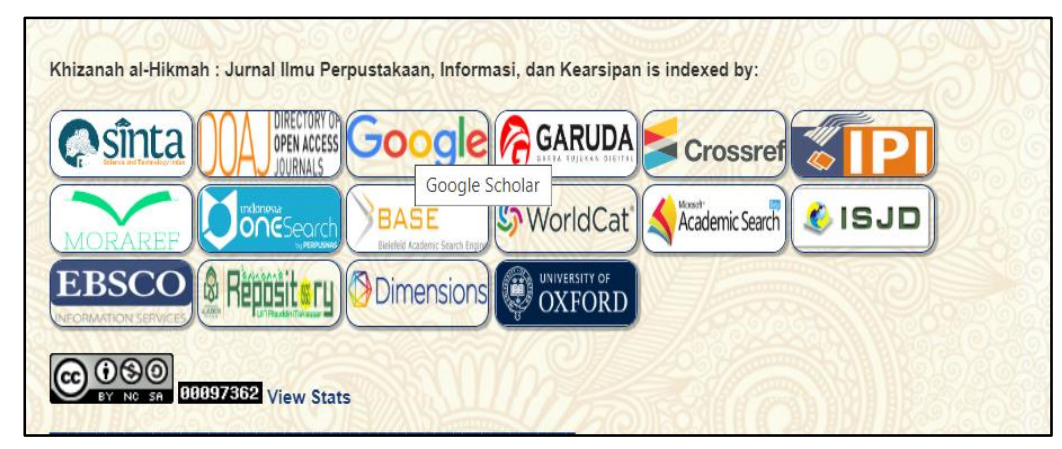

Gambar 1. GSM yang terlihat pada bagian footer KAH-JIPIK (Sumber: http://journal.uinalauddin.ac.id/index.php/khizanah-al-hikmah/index)

Kutip mengutip ialah sesuatu yang sudah lazim pada dunia akademik atau publikasi. Ini tidak lain untuk memberikan kredit kepada tiap-tiap karya yang dikutip. Junandi (2016) mengatakan bahwa penulisan karya ilmiah tidak dapat melepaskan diri dari keharusan menggunakan berbagai sumber literatur bahan pustaka sebagai kutipan atau sitiran. Begitu pula yang disebutkan oleh Rahmah (2011). Selanjutnya, menurut Lawe dalam (Suradkar \& Khaparde, 2012), "Citation analysis/reference are a method of determining a characteristic of a field or a subject by careful examination of the literature of that area. It is based on the principle that "the actual use of material is indicative of its relevance to current research". Lanjutnya, ada dua tujuan di mana analisis sitasi dapat dilakukan, yakni; Pertama, untuk teoretical, yakni berguna untuk mengenali perkembangan literatur sebagaimana mereka akan memberikan dampak pada bibliografi (bahanbahan bacaan) dan hal-hal terkait anggaran, dan Kedua, untuk hal yang lebih spesifik yang 
memungkinkan sebuah profesi pada disiplin ilmu tertentu mendapatkan pengetahuan tentang spesifikasi bidang mereka.

Dalam Rahardja et al., (2016), menulis dokumen secara digital dipesatnya perkembangan teknologi saat ini, sudah banyak dilakukan oleh para mahasiswa. Namun, mencari sumber referensi yang valid dan mengetahui apakah tulisan tersebut mengandung unsur plagiarism atau tidak masih mengalami banyak kendala. Terkadang mahasiswa masih banyak yang mencari referensi dari sumber yang belum terpercaya, padahal hal tersebut dapat menjadi hal yang sangat fatal untuk penulisan laporan Tugas Akhir dan Skripsi. Oleh karena itu Google dengan Google Scholar-nya menjadi media yang tepat untuk menelusuri informasi dan referensi yang valid dan terpercaya. Selain itu, para pencari informasi juga dapat menelusuri rekam publikasi tiap penulis atau jurnal ilmiah dengan melihatnya pada Google Scholar Profile, seperti pada contoh di bawah ini.

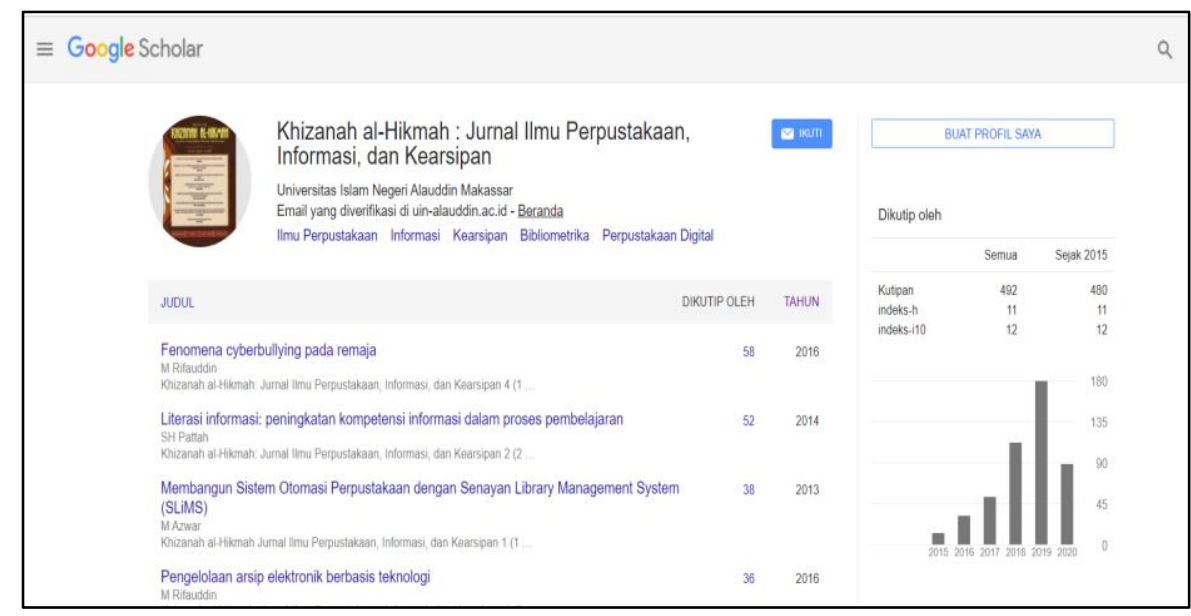

Gambar 2. Profil KAH-JIPIK yang menunjukkan rekam publikasi artikel-artikel yang telah diterbitkan (Sumber: https://scholar.google.com/citations?hl=id\&user=yBLPjbAAAAAI)

Noruzi (2005) mengatakan "Google Scholar provides a new method of locating potentially relevant articles on a given subject by identifying subsequent articles that cite a previously published article". Fitur GS ini sangat penting bagi para akademisi, dosen maupun peneliti di mana mereka dapat menggunakannya untuk men'trace' atau mengetahui inter koneksi antar artikel yang dikutip. Bagi perpustakaan, analisis seperti ini dapat digunakan untuk mengevaluasi koleksi perpustakaan (Hayati, 2018). Oleh karena itu, analisis sitiran (Jacobs dalam Muntashir \& Erida, (2018), Reitz, (2004), Hayati, (2018), Amelia \& Hakim, (2016), Nurochman, Romadon, Hariyadi, Kurniasih \& Kasworini, (2018)) sangat penting sebagai alat evaluasi, yang dalam penelitian ini dikhususkan pada jurnal ilmiah.

Penulisan artikel ini bertujuan untuk melihat tren (Ashry \& Fitra, 2019) sitiran artikel, dokumen yang menyitir artikel dan artikel yang sering disitir pada Khizanah Al-Hikmah : Jurnal Ilmu Perpustakaan, Informasi, dan Kearsipan berdasarkan Google Scholar Metrics.

\section{METODOLOGI PENELITIAN}

Penelitian ini adalah penelitian deskripsi kuantitatif-kualitatif dengan menggunakan pendekatan bibliometrika. Data penelitian diperoleh melalui Google Scholar Metrics beserta dengan perhitungannya. Saat ini, terdapat 109 artikel yang dijadikan data penelitian terbit dari tahun 2013 hingga Volume 7 Nomor 1 tahun 2019. Untuk membantu visualisasi data, MS. Excel digunakan menampilkan tabel. Selain data kuantitatif tersebut, data kualitatif juga diperoleh melalui wawancara mendalam dengan manajer jurnal KAH-JIPIK terkait manfaat yang dirasakan dengan adanya GSM pada pengelolaan jurnal. 


\section{HASIL DAN PEMBAHASAN}

Dari seluruh artikel yang ada di Khizanah Al-Hikmah: Jurnal Ilmu Perpustakaan, Informasi dan Kearsipan, mulai dari tahun 2013 hingga pertengahan 2019, terdapat 13 volume, 13 nomor, dan 109 artikel.

Tabel 1. Publikasi Artikel KAH-JIPIK Tahun 2013-2019

\begin{tabular}{|c|c|c|c|c|c|}
\hline Tahun & Volume & Nomor & Artikel & $\begin{array}{c}\text { Jumlah } \\
\text { Terbitan/Tahun }\end{array}$ & $\begin{array}{c}\text { Jumlah } \\
\text { Artikel/ } \\
\text { Tahun } \\
\end{array}$ \\
\hline \multirow[t]{2}{*}{2013} & 1 & 1 & 8 & 2 & 16 \\
\hline & 1 & 2 & 8 & 2 & \\
\hline \multirow[t]{2}{*}{2014} & 2 & 1 & 8 & 2 & 16 \\
\hline & 2 & 2 & 8 & 2 & \\
\hline \multirow[t]{2}{*}{2015} & 3 & 1 & 8 & 2 & 16 \\
\hline & 3 & 2 & 8 & 2 & \\
\hline \multirow[t]{2}{*}{2016} & 4 & 1 & 8 & 2 & 16 \\
\hline & 4 & 2 & 8 & 2 & \\
\hline \multirow[t]{2}{*}{2017} & 5 & 1 & 12 & 2 & 21 \\
\hline & 5 & 2 & 9 & 2 & \\
\hline \multirow[t]{2}{*}{2018} & 6 & 1 & 8 & 2 & 16 \\
\hline & 6 & 2 & 8 & 2 & \\
\hline 2019 & 7 & 1 & 8 & 1 & 8 \\
\hline Jumlah & 13 & 13 & 109 & 13 & 109 \\
\hline
\end{tabular}

\section{Tren Penurunan Sitiran}

Tabel 2. Penurunan Jumlah Sitasi/Tahun

\begin{tabular}{cc}
\hline \multicolumn{2}{c}{ Penurunan Jumlah Sitasi } \\
\hline Tahun & Sitasi \\
2013 & 105 \\
2014 & 75 \\
2015 & 24 \\
2016 & 63 \\
2017 & 13 \\
2018 & 8 \\
Nomor 1 Tahun 2019 & 1 \\
\hline Jumlah & $\mathbf{2 8 1}$ \\
\hline Sumber: Data Hasil Penelitian, 2019
\end{tabular}

Tabel di atas menggambarkan bagaimana perolehan sitasi mengalami penurunan dari tahun ke tahun. Sangat kontras terlihat penurunan jumlah sitiran pada tahun pertama dan tahun terakhir yaitu dari 105 turun hingga ke hanya 1 sitiran saja. Grafik di bawah memberikan gambaran yang lebih jelas lagi. 
Grafik 1. Tren Penurunan Sitiran Artikel Khizanah Al-Hikmah

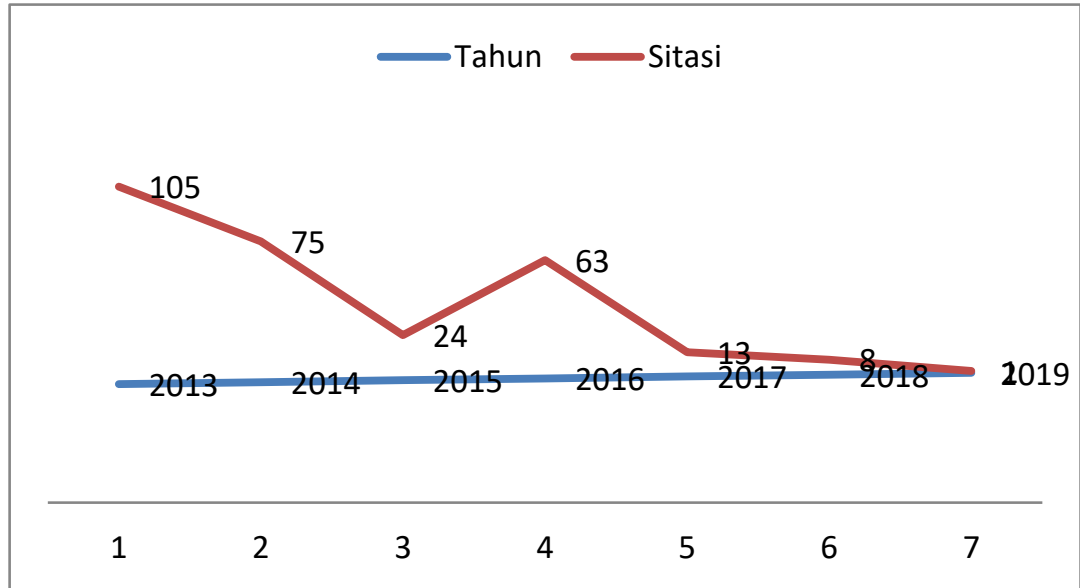

Sumber: Data Hasil Penelitian, 2019

\section{Jenis Dokumen yang Menyitir}

Dari 109 artikel yang telah diterbitkan jurnal ini, berikut jenis atau bentuk dokumen yang menyitir artikel-artikel di KAH-JIPIK. Berikut tabel jumlah sitiran pada artikel Khizanah AlHikmah mulai dari sitiran tertinggi hingga sitiran terendah dari tahun yang berbeda.

Tabel 3. Jenis Literatur yang Menyitir dan Perolehan Sitiran

\begin{tabular}{cc}
\hline Jenis Literatur & Perolehan Sitiran \\
\hline Jurnal & 178 \\
Skripsi & 81 \\
Tesis & 1 \\
Prosiding & 8 \\
Makalah & 1 \\
Buku & 3 \\
Sumber Lain & 9 \\
\hline Jumlah & $\mathbf{2 8 1}$
\end{tabular}

Sumber: Data Hasil Penelitian, 2019

\section{Artikel yang Sering Disitir}

Tabel4. Top 10 Rangking Jumlah Sitasi yang Paling Sering Disitir

\begin{tabular}{lcc}
\hline \multicolumn{1}{c}{ Nama } & Jumlah Sitiran & Tahun \\
\hline Machsun Rifauddin & 30 & 2016 \\
Sitti Husaebah Pattah & 26 & 2013 \\
Sitti Husaebah Pattah & 23 & 2014 \\
Muhammad Azwar & 22 & 2013 \\
Muhammad Azwar & 16 & 2014 \\
M. Rifauddin & 13 & 2016 \\
R. Rodin & 13 & 2013 \\
Fadhilatul Hamdani & 9 & 2014 \\
Andi Ibrahim & 8 & 2014 \\
Touku Umar & 8 & 2013 \\
\hline
\end{tabular}

Sumber: Data Hasil Penelitian, 2019 


\section{Afiliasi Lembaga Penyumbang Tulisan}

Tabel 5. Afiliasi/Lembaga para Penulis Artikel

\begin{tabular}{|c|c|c|}
\hline No & Afiliasi Lembaga & $\begin{array}{l}\text { Jumlah } \\
\text { Penulis }\end{array}$ \\
\hline 1 & Universitas Islam Negeri Alauddin, Makassar & 29 \\
\hline 2 & Universitas Padjajaran, Bandung & 15 \\
\hline 3 & Lembaga Ilmu Pengetahuan Indonesia, Jakarta & 12 \\
\hline 4 & Universitas Indonesia, Jakarta & 11 \\
\hline 5 & Universitas Islam Negeri Sunan Kalijaga, Yogyakarta & 11 \\
\hline 6 & Universitas of Malaya, Malaysia & 7 \\
\hline 7 & Universitas Gadjah Mada, Bandung & 5 \\
\hline 8 & Universiti Sains Islam, Malaysia & 4 \\
\hline 9 & Universitas Mataram & 3 \\
\hline 10 & Universitas Islam Negeri Syarif Hidayatullah Jakarta & 3 \\
\hline 11 & Universitas Pembangunan Nasional "Veteran", Jawa Timur & 2 \\
\hline 12 & IAIN Tulungagung & 2 \\
\hline 13 & Akademi Keperawatan Notokusumo, Yogyakarta & 2 \\
\hline 14 & Kantor Arsip dan Perpustakaan Daerah Yogyakarta & 2 \\
\hline 15 & University Teknologi MARA (UiTM) Selangor & 2 \\
\hline 16 & Universitas Islam Negeri Imam Bonjol, Padang & 1 \\
\hline 17 & Universitas Wijaya Kusuma, Surabaya & 1 \\
\hline 18 & Universitas Islam Nusantara & 1 \\
\hline 19 & Dinas Kearsipan dan Perpustakaan Kab. Wonosobo & 1 \\
\hline 20 & Women Crisis Center Yogyakarta & 1 \\
\hline 21 & Perpustakaan Puslitbangtek Migas "LEMIGAS" & 1 \\
\hline 22 & Balai Penelitian Kehutanan, Kupang & 1 \\
\hline 23 & Universitas Muhammadiyah, Magelang & 1 \\
\hline 24 & Universitas Sultan Ageng Tirtayasa & 1 \\
\hline 25 & PT. Chevron Pacific Indonesia & 1 \\
\hline 26 & Universitas Tanjungpura, Pontianak & 1 \\
\hline 27 & Perpustakaan Nasional RI & 1 \\
\hline 28 & Kementerian Keuangan & 1 \\
\hline 29 & Kemenristek Institut Seni (ISI) Solo & 1 \\
\hline 30 & Balai Diklat Keagamaan Semarang & 1 \\
\hline 31 & STAI Pamekasan & 1 \\
\hline 32 & SMAN 2 Liukang Kalakuang Masalima & 1 \\
\hline 33 & SMA 1 Bantaeng & 1 \\
\hline 34 & Universitas Pembangunan Nasional Veteran Jakarta & 1 \\
\hline 35 & Universitas Atma Jaya Yogyakarta & 1 \\
\hline 36 & STKIP PGRI Lubuklinggau Palembang & 1 \\
\hline 37 & SMAN 1 Yogyakarta & 1 \\
\hline 38 & Pusdiklat Kemenag & 1 \\
\hline 39 & STAIN Padan Sidimpuan & 1 \\
\hline 40 & Universitas Pelita Harapan & 1 \\
\hline
\end{tabular}




\section{Manfaat GSM pada Pengelolaan KAH-JIPIK}

Google Scholar Metrics yang pada umumnya membantu para penulis untuk mengukur visibilitas dan pengaruh artikel-artikel yang terpublikasi juga dapat bermanfaat bagi jurnal-jurnal ilmiah. Setiap jurnal, dengan GSM dapat mengukur seberapa banyak sitasi yang telah diperolahnya dan mengetahui artikel-artikel mana saja yang sering dikutip. Beberapa peneliti menggunakan GSM untuk melakukan kajian bibliometrika. Untuk manfaat yang dirasakan oleh KAH-JIPIK sendiri, dari hasil wawancara dengan manajer jurnal, Hijrana bahwa "dengan GSM, kami dapat melihat tren perkembangan sitasi dari tahun ke tahun. Dari statistik tersebut yang dapat kami gunakan untuk mempertimbangkan artikel-artikel yang akan diterbitkan dan membuat strategi tematik jurnal untuk edisi berikutnya". Artinya, pengelola jurnal akan lebih selektif lagi dalam memilih dan memilah artikel yang diterima dan akan diterbitkan.

KAH-JIPIK yang hingga saat ini telah menerbitkan sebanyak 109 artikel sejak tahun 2013 lalu, dan semua artikel tersebut telah terindeks pada profil GS KAH-JIPIK, sehingga metrik yang ada menampilkan tren sitasinya dan juga bisa dijadikan sebagai dasar pertimbangan untuk menentukan tema artikel yang akan diterima pada edisi-edisi berikutnya. "GSM membantu kami menentukan haluan akan tema-tema selanjutnya", menurut Hijrana. Selain itu, editor jurnal dituntut untuk selalu update mengamati isu-isu kekinian agar dapat meningkatkan daya saing lagi agar dilirik oleh penulis yang berkualitas sehingga tulisan yang dikirim ke redaksi jurnal tidak membutuhkan banyak revisi lagi.

\section{KESIMPULAN}

Tren jumlah sitasi yang diperolah pada artikel-artikel yang diterbitkan KAH-JIPIK terjadi penurunan dari tahun ke tahun kecuali pada tahun 2016. Namun demikian, berdasarkan tahun, jumlah sitasi menunjukkan tren yang meningkat. Jenis-jenis dokumen yang banyak menyitir artikel-artikel pada KAH-JIPIK adalah jurnal, skripsi, tesis, prosiding, makalah, buku dan sumber lainnya. Artinya, banyak mahsiswa program S1, khususnya pada rumpun ilmu informasi, perpustakaan, dan kearsipan menjadikan jurnal ini sebagai salah satu rujukan. Sementara untuk artikel yang paling sering disitir adalah artikel yang ditulis oleh Machsun Rifauddin yang berjudul "Fenomena cyberbullying pada remaja" dengan jumlah sitiran sebanyak 30 sitiran ketika penelitian ini dilakukan. Isu cyberbullying memang marak diperbincangkan ketika itu. Sementara untuk pengaruh GSM bagi pengelolaan jurnal ternyata cukup besar. Dari GSM ini, jurnal ilmiah bisa mengamati tren perkembangan sitasi dan menjadi dasar dari penentuan tema untuk edisiedisi yang akan diterbitkan.

\section{DAFTAR PUSTAKA}

Amelia, V., \& Hakim, T. D. (2016). Analisis sitiran pada jurnal di lingkungan Unilak periode 20132015. Jurnal Pustaka Budaya. 3(2).

Ashry, L. Al, \& Fitra, H. (2019). Pengaruh Pertumbuhan Penjualan dan Profitabilitas Terhadap Struktur Modal pada Perusahaan Real Estate and Property di Bursa Efek Indonesia. Jurnal Kajian Manajemen dan Wirausaha, 1(1).

Hayati, N. (2018). Citation Analisis as a Tool of Library Collections Evaluation. Record and Library Journal, 2(1), 1. https://doi.org/10.20473/rlj.v2-i1.2016.1-15

Junandi, S. (2016). Analisis Sitiran Karya Ilmiah Pustakawan Indonesia pada Jurnal Visi Pustaka Tahun 2008-2013. Berkala Ilmu Perpustakaan Dan Informasi, 11(1), 45-54. https://jurnal.ugm.ac.id/bip/article/view/8840

Karmila, A. K. (2019). Khizanah al-Hikmah : Jurnal Ilmu Perpustakaan, Infomasi, dan Kearsipan, How It Manages?. Literatify : Trends in Library Developments, 1(1), 8-14. http://journal.uinalauddin.ac.id/index.php/literatify/article/view/13094

Lariviere, V., \& Sugimoto, C. R. (2018) The journal impact factor: a brief history, critique, and discussion, of adverse effects. https://arxiv.org/ftp/arxiv/papers/1801/1801.08992.pdf

Muntashir, M., \& Erida, E. (2018). Analisis sitiran dan pemetaan deskriptor terhadap disertasi Program Pascasarjana Universitas Islam Negeri Imam Bonjol. Shaut Al-Maktabah : Jurnal Perpustakaan, Arsip Dan Dokumentasi, 10(1), 1-26. https://doi.org/10.15548/SHAUT.V10I1.2 
Noruzi, A. (2005). Google Scholar : the new generation of citation indexes.

Nurochman, A., Romadon., Hariyadi, A., Kurniasih, W., \& Kasworini, E. (2018). Analisis sitiran skripsi Jurusan Kedokteran Umum tahun 2016 dan ketersediaannya di Perpustakaan Fakultas Kedokteran Universitas Jenderal Soedirman. BACA: JURNAL DOKUMENTASI DAN INFORMASI. 39(1).

Rahardja, U., Tiara, K., \& Rosalinda, I. A. (2016). Pemanfaatan Google Scholar Dan Citation Dalam Memenuhi Kebutuhan Pembuatan Skripsi Mahasiswa Pada Perguruan Tinggi. Technomedia Journal. https://doi.org/10.33050/tmj.v1i1.28

Rahmah, E. (2011). Kajian Bibliometrika Menggunakan Analisis Sitiran terhadap Skripsi Program Studi Pendidikan Bahasa dan Sastra Indonesia FBS UNP Tahun 2005-2009. Komposisi: Jurnal $\begin{array}{lllll}\text { Pendidikan Bahasa, Sastra, } & \text { Dan }\end{array}$ https://doi.org/10.24036/komposisi.v12i2.3916

Reitz, J. (2004). Library and Information Science. Greenwood Publishing Group.

Suradkar, P., \& Khaparde, V. (2012). Bibliometric Analysis: The Electronic Library. LAP LAMBERT Academic Publishing.

What is Google Scholar? What is it for? - Getting Better Results with Google Scholar - Research Guides at University of Arkansas. (n.d.). Retrieved June 30, 2020, from https://uark.libguides.com/googlescholar 